\title{
INFLUÊNCIA DA CARDIOLIPINA NA PRODUÇÃO DE ÁCIDO HIALURÔNICO UTILIZANDO PEPTONA DE SOJA OU EXTRATO DE LEVEDURA COMO FONTES DE NITROGÊNIO EM FERMENTAÇÕES SUBMERSAS
}

\author{
D. S. P. MOREIRA ${ }^{1}$, R. C. OLIVEIRA ${ }^{1}$, M. H. A. SANTANA ${ }^{1}$ \\ ${ }^{1}$ Universidade Estadual de Campinas, Faculdade de Engenharia Química \\ E-mail para contato: daniela.pataro.m@gmail.com
}

\begin{abstract}
RESUMO - O ácido hialurônico (AH) é um polissacarídeo linear com diversas aplicações nas áreas biomédicas e farmacológicas. Este trabalho teve por objetivo estudar a influência da cardiolipina na produção do AH através de fermentação submersa utilizando o Streptococcus zooepidemicus ATTC 39920. O meio de cultura foi composto de glicose $\left(25\right.$ g.L $\left.\mathrm{L}^{-1}\right)$, como fonte de carbono e peptona de soja ou extrato de levedura, como fontes de nitrogênio e cardiolipina (30 mg.L $\left.\mathrm{L}^{-1}\right)$ Cultivos na ausência de cardiolipina foram usados como controle. O desempenho das fermentações foi analisado em termos de concentração celular, concentração de $\mathrm{AH}$ e rendimento $\mathrm{Y}_{\mathrm{P} / \mathrm{X}}(\mathrm{AH} /$ células). Dos resultados obtidos concluiu-se que a cardiolipina elevou significativamente a produção de $\mathrm{AH}$, principalmente quando a fonte de nitrogênio foi a peptona de soja.
\end{abstract}

\section{INTRODUÇÃO}

O ácido hialurônico (AH) é um polissacarídeo formado por repetidas unidades dissarídicas de ácido D-glicurônico e $\mathrm{N}$-acetilglicosamina unidas através de ligações glicosídicas $\beta-1-3$ e $\beta$-1-4. O ácido hialurônico é um dos componentes da matriz extracelular dos vertebrados e está presente principalmete em cartilagens, cordão umbilical, pele, humor vítreo e fluido sinovial. Devido a sua alta retenção de água, viscoelasticidade e biocompatibilidade, o AH possui diversas aplicações farmacêuticas, médicas e cosméticas.

Bactérias do gênero Streptococcus também produzem AH. O AH produzido por via microbiana é puro, biocompatível e apresenta as mesmas propriedades do AH produzido em humanos. Nesses microrganismos o AH é sintetizado no interior das células e excretado através da membrana celular, formando uma barreira que protege a célula do stress causado pelo meio ao qual está exposta.

Na produção do $\mathrm{AH}$, a enzima hialuronidase sintase (HAS) é responsável pela síntese e elongação da cadeia de $\mathrm{AH}$, essa enzima também participa do processo de extrusão do $\mathrm{AH}$ através da membrana celular. Como a membrana celular é constituída por uma parte hidrofóbica e uma parte lipídica, Weigel (1998) concluiu que a cardiolipina age juntamente com a enzima HAS na extrusão do $\mathrm{AH}$, ou seja, a parte lipídica da cardiolipina interagiria com a bicamada lipídica da membrana bacteriana e as porções hidrofóbicas da cadeia de $\mathrm{AH}$, enquanto os grupos acídicos da cardiolipina interagiriam com a enzima e as porções 
hidrofílicas da cadeia de AH. Assim, os fosfolipídeos e as enzimas criariam uma passagem na membrana na forma de poro, através do qual o AH sintetizado seria mais facilmente extrudado. Um esquema da atuação da cardiolipina juntamente com a enzima HAS pode ser visto na Figura 1.

Figura 1 - Modelo para o complexo cardiolipina - hialuronidase sintase (Weigel, 1998).

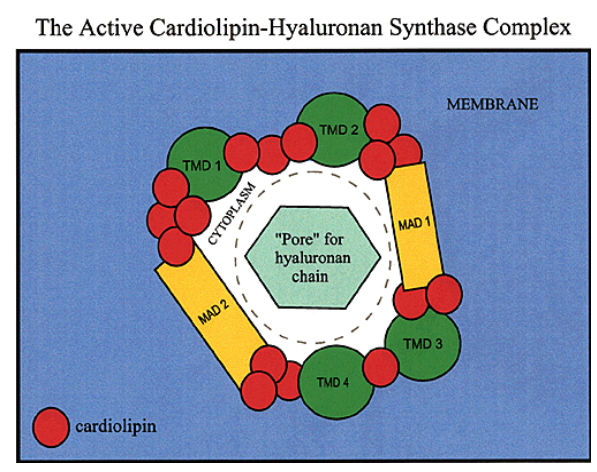

Nos últimos 10 anos, a indústria farmacêutica e cosmética tem se posicionado contra a utilização de fontes de origem animal em cultivos microbianos por razões de segurança. Pires et al. (2010), utilizaram derivados agrícolas em meios de cultura para a produção de $\mathrm{AH}$, o suco de caju em conjunto com o extrato de levedura foi considerado um meio promissor para a produção de $\mathrm{AH}$, com uma concentração de 0,89 g.L.-1 em cultivos com aeração natural. Benedini e Santana (2012) demonstraram a eficiência de peptona de soja como fonte de nitrogênio em cultivos com aeração natural utilizando extrato de levedura e glicose como controle.

Considerando o mecanismo proposto por Weigel (1998) e a importância da fonte de nitrogênio na produção do $\mathrm{AH}$, este trabalho foi conduzido de modo a avaliar o efeito da cardiolipina em fermentações com extrato de levedura ou peptona de soja como fontes de nitrogênio.

\section{OBJETIVO}

Estudar os efeitos da cardiolipina na produção do ácido hialurônico por fermentação submersa utilizando o Streptococcus zooepidemicus, em meios de cultura contendo glicose como fonte de carbono e peptona de soja ou extrato de levedura como fonte de nitrogênio.

\section{MATERIAIS E MÉTODOS}

\subsection{Microrganismos}

Uma cepa do microrganismo Streptococcus equi, subsp. zooepidemicus ATCC 39920, obtida através da American Type Culture Collection (ATCC, Manassas, VA, EUA) como cultura liofilizada, foi mantida congelada a $-80^{\circ} \mathrm{C}$, em ampolas contendo glicerol $(10 \%)$ como crioprotetor. 


\subsection{Inóculo}

Uma ampola contendo a cultura de Streptococcus equi subsp. Zooepidemicus ATCC 39920 foi descongelada e semeada em placas de Petri contendo agar e peptona de soja $\left(67 \mathrm{~g}\right.$. $\mathrm{L}^{-}$ ${ }^{1}$ ) (Benedini e Santana 2013) e incubadas a $37^{\circ} \mathrm{C}$ durante $24 \mathrm{~h}$. As colônias foram transferidas das placas de Petri para frascos Erlenmeyer $(50 \mathrm{~mL})$ contendo $10 \mathrm{~mL}$ de meio de cultura. Esses frascos foram incubados sob agitação $(150 \mathrm{rpm})$ a $37^{\circ} \mathrm{C}$, durante $12 \mathrm{~h}$. Em dois dos frascos Erlenmeyer o cultivo foi conduzido com glicose e peptona de soja e nos outros dois com extrato de levedura e glicose. A razão glicose : nitrogênio utilizada foi de 4,3: 1 para todos os cultivos.

\subsection{Fermentação}

O inóculo foi transferido a 10\% v/v para os frascos Erlenmeyer $(250 \mathrm{~mL})$, contendo as mesmas concentrações de glicose, peptona de soja ou extrato de levedura. A cardiolipina foi adicionada na concentração $30,0 \mathrm{mg} . \mathrm{L}^{-1}$. No total foram realizadas 8 fermentações. Todos os frascos foram incubados a $150 \mathrm{rpm}, 37^{\circ} \mathrm{C}$, durante $24 \mathrm{~h}$. Ao final deste período foram coletadas amostras para as análises em triplicata.

\subsection{Separação e Purificação do AH}

O caldo fermentado foi centrifugado a $3200 \mathrm{rpm}$ durante 20 minutos. O sobrenadante isento de células foi tratado com etanol a 1.5:1 v/v (etanol : caldo). A solução foi refrigerada a $4{ }^{\circ} \mathrm{C}$ durante $1 \mathrm{~h}$ para a precipitação do $\mathrm{AH}$, e em seguida foi centrifugada novamente a 3200 rpm durante 20 minutos. Uma solução de $\mathrm{NaCl} 0.15 \mathrm{~mol}^{-1}$ foi adicionada ao $\mathrm{AH}$ precipitado. O processo de precipitação com etanol e centrifugação da solução refrigerada foi realizado por mais duas vezes consecutivas.

\subsection{Métodos Analíticos}

Crescimento celular: $\mathrm{O}$ crescimento celular foi determinado em triplicata de acordo com o método gravimétrico. Ao final da fermentação, uma amostra contendo $10 \mathrm{~mL}$ do caldo fermentado foi retirada e centrifugada em tubo previamente seco e pesado. Após a centrifugação o caldo residual foi separado e as células lavadas com água deionizada e centrifugada mais duas vezes. Finalmente, as células foram secas e pesadas para o método gravimétrico.

Concentração de AH: Foi aplicado o método turbidimétrico para determinar o teor de ácido hialurônico no caldo fermentado como descrito por Chen e Wang (2009). Hialuronato de sódio (Hylumed TM) da Genzyme Corporation (Cambridge, MA, EUA) foi utilizado como padrão. Todas as análises foram realizadas em triplicata.

Os resultados finais de concentração celular e concentração de $\mathrm{AH}$ representam a média aritmética da duplicata dos cultivos. 


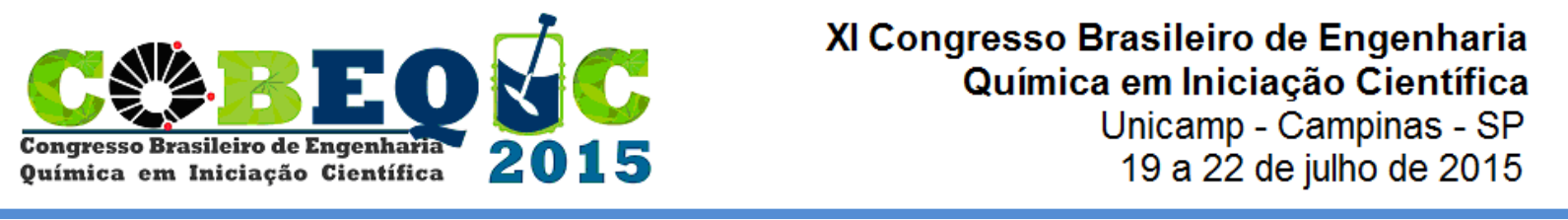

\section{RESULTADOS E DISCUSSÃO}

A Figura 2 (a) mostra a influência da cardiolipina na concentração celular e a Figura 2 (b) na concentração de $\mathrm{AH}$. Os resultados mostram claramente um aumento da concentração de AH com a adição de cardiolipina no meio de cultura contendo peptona de soja, comparado ao meio contendo extrato de levedura. Os efeitos da cardiolipina na concentração celular foram menos expressivos.

Figura 2 - (a) Concentração celular e (b) Concentração de AH. Legendas: PSC (Peptona de soja sem cardiolipina), PCC (Peptona de soja com cardiolipina), ESC (Extrato de levedura sem cardiolipina) e ECC (Extrato de levedura com cardiolipina).

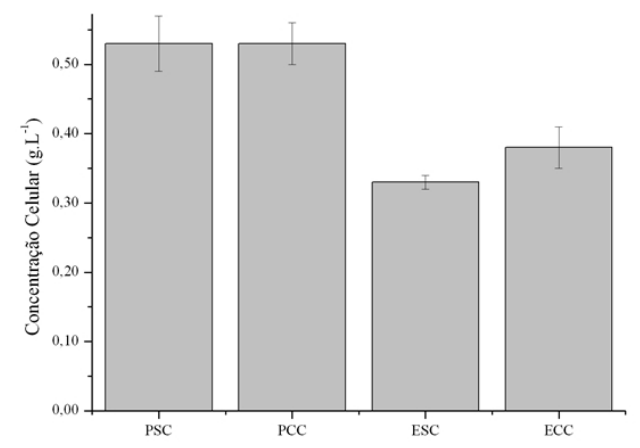

(a)

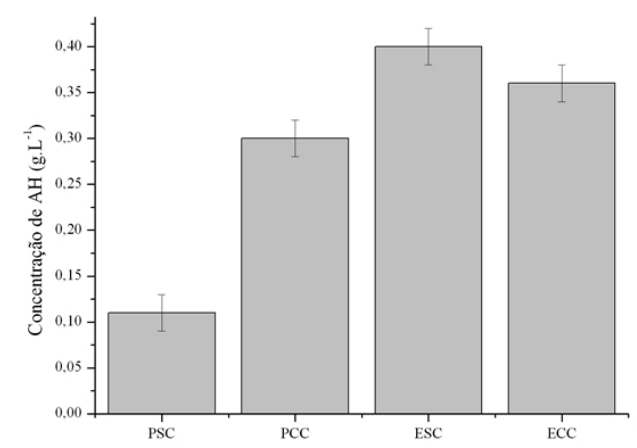

(b)

Em ambos os casos os resultados mostram que quanto maior a concentração celular, menor a produção de ácido hialurônico. Isso ocorre devido a utilização da energia para o crescimento celular em detrimento da produção do $\mathrm{AH}$, nesse caso o extrato de levedura apresentou melhores resultados em termos de rendimento, que representa a quantidade de $\mathrm{AH}$ produzida em relação às células $\left(\mathrm{Y}_{\mathrm{P} / \mathrm{X}}\right)$. A Figura 3 exibe a influência da cardiolipina no rendimento $\mathrm{Y}_{\mathrm{P} / \mathrm{X}}$.

Figura 3 - Influência da cardiolipina no rendimento $\mathrm{Y}_{\mathrm{P} / \mathrm{X}}$. Legendas: PSC (Peptona de soja sem cardiolipina), PCC (Peptona de soja com cardiolipina), ESC (Extrato de levedura sem cardiolipina) e ECC (Extrato de levedura com cardiolipina). 


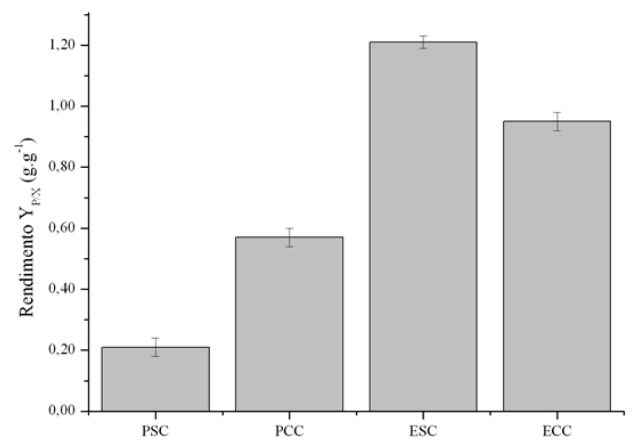

Com relação ao rendimento $\mathrm{Y}_{\mathrm{P} / \mathrm{X}}$, o meio de cultura contendo peptona de soja e glicose exibiu um aumento de aproximadamente 3 vezes com a adição de cardiolipina em relação ao controle (Figura 3). O meio de cultura contendo extrato de levedura e glicose resultou em uma queda de rendimento $\mathrm{Y}_{\mathrm{P} / \mathrm{X}}$ de aproximadamente $16 \%$ com a adição de cardiolipina em relação ao controle.

Comparando os resultados dos dois meios de cultura utilizados, podemos observar uma nítida vantagem do extrato de levedura em relação a peptona de soja em termos de rendimento na produção de $\mathrm{AH}$ (Figura 3). Esta vantagem pode estar relacionada à concentração de aminoácidos livres presentes no extrato de levedura, sendo este um parâmetro importante para a produção de AH segundo Armstrong et al. (1997). No entanto, a utilização de fontes vegetais de meio de cultura pode proporcionar vantagens para a purificação e comercialização do $\mathrm{AH}$, principalmente para aplicações farmacêuticas. Além disso a massa molar, um parâmetro muito importante na produção de $\mathrm{AH}$ deve ser futuramente avaliada na presença das duas fontes de nitrogênio utilizadas neste trabalho e da cardiolipina.

\section{CONCLUSÃO}

A utilização de cardiolipina em meio de cultura contendo peptona de soja e glicose, aumentou a produção de $\mathrm{AH}$ em fermentação submersa utilizando o Streptococcus zooepidemicus.

\section{NOMENCLATURA}

AH - Ácido hialurônico

ECC - Extrato de levedura com cardiolipina

ESC - Extrato de levedura sem cardiolipina

HAS - Hialuronidase sintase

PCC - Peptona de soja com cardiolipina

PSC - Peptona de soja sem cardiolipina

\section{REFERÊNCIAS}


ARMSTRONG, D. C.; COONEY, M. J.; JOHNS, M. R. Growth and amino acid requirements of hyaluronic-acid-producing Streptococcus zooepidemicus. Applied Microbiology

Biotechnology, v. 47, p. 309-312, 1997.

BENEDINI, L. J.; SANTANA M. H. A. Efects of vegetables peptones on the microbial production and purity of hyaluronic acid. State University of Campinas. (MSc. Thesis), 2012.

BENEDINI, L. J.; SANTANA M. H. A. Effects of soy peptone on inoculums preparation of Streptococcus zooepidemicus for production of hyaluronic acid. State University of Campinas.(MSc. Thesis). 2013.

CHEN, Y. H.; WANG, Q. Establishment of CTAB Turbidimetric method to determine hyaluronic acid content in fermentation broth. Carbohydrate Polymers. 78, p. 178-181, 2009.

PIRES, A. M. B.; MACEDO, A. C.; EGUCHI, S. Y.; SANTANA, M. H. A. Microbial production of hyaluronic acid from agricultural resource derivatives. Bioresource Technology. v. 101. p. 6506-6509, 2010.

WEIGEL, P. H. Bacterial Hyaluronan Synthases: Glycoforum - Hyaluronan Today. Original Issue August 15, 1998. Disponível em: $<$ http://www.glycoforum.gr.jp/science/hyaluronan/HA06/HA06E.html>. 